\title{
Assessment of Vitamin D status in a group of Egyptian children with non alcoholic fatty liver disease (multicenter study)
}

\author{
Amal Mohamed Ahmed', Maha Abdel Ghany ${ }^{2}$, Gehan Lotfy Abdel Hakeem ${ }^{3}$, Aya Kamal ${ }^{4}$, Rania Khattab ${ }^{5}$, \\ Asmaa Abdalla ${ }^{6}$, Laila El Morsi Abou El Fotoh ${ }^{3}$, Abdel Azeem El Mazary ${ }^{3}$, Madiha Abdalla Sayed ${ }^{3}$ and \\ Ashraf Mohamed Abdel Fadil ${ }^{3}$
}

\begin{abstract}
Background: Nonalcoholic fatty liver disease (NAFLD) is one of the health problems with great burden on the liver that may end with liver cirrhosis and hepatocellular carcinoma. The aim of this work was to assess serum vitamin D level in nonalcoholic fatty liver disease children

Methods: This cross sectional case control study involved 47 patients with nonalcoholic fatty liver disease selected while recruiting the pediatric hepatology clinics. Their ages ranged from 5-15 years and were compared with 23 healthy age and sex matched children. All involved patients were subjected to careful history taking, clinical examination and for patients and control, anthropometric measures for body mass index (BMI) calculation (plotted on WHO percentile growth charts), aspartate aminotransferase (AST), alanine aminotransferase (ALT), alkaline phosphatase (ALP), gamma glutamyl transferase (GGT), bilirubin (total and direct), serum albumin, creatinine, triglycerides, cholesterol, high density lipoprotein (HDL), low density lipoprotein (LDL), fasting blood glucose and fasting insulin (for calculation of insulin resistance), C reactive protein and serum vitamin $D$ all were assayed. NAFLD was detected by ultrasonography and graded as absent, mild, moderate and severe.

Results: Ninety-three percent of NAFLD patients were obese. Significant differences were found between patients and control regarding AST, ALT, ALP, GGT, total and direct bilirubin, serum albumin, creatinine, triglycerides, cholesterol, $\mathrm{HDL}$, fasting blood glucose, fasting insulin, the homeostatic model assessment for insulin resistance (HOMA-IR) and serum vitamin D levels. Significant negative correlation was found between serum vitamin D level and grades of steatosis.
\end{abstract}

Conclusions: Serum vitamin D level decreases in children with NAFLD. This low serum vitamin D level is associated with higher stages of steatosis but not with BMI.

Keywords: Nonalcoholic fatty liver disease, Vitamin D, Children

\section{Background}

Vitamin $\mathrm{D}$ is a fat-soluble vitamin formed in the skin from 7-dehydrocholestrol during exposure to solar ultraviolet B (UVB) radiation [1]. 25-hydroxyvitamin D $[25(\mathrm{OH}) \mathrm{D}]$ is the major circulating metabolite used as indicator of vitamin D stores [2] which is furtherly metabolized in the kidneys to the biologically active form, dihydroxy vitamin $\mathrm{D}\left[1,25(\mathrm{OH})_{2} \mathrm{D}\right]$. Vitamin $\mathrm{D}$ deficient

\footnotetext{
* Correspondence: gehanlotfy72@yahoo.com

${ }^{3}$ Pediatric Department, Minia University, El Minya, Egypt

Full list of author information is available at the end of the article
}

individuals are more likely to develop alterations in glucose metabolism as impaired glucose tolerance, metabolic syndrome and type 2 diabetes mellitus [3-5]. Based on these evidences, it can be hypothesized that vitamin D deficiency should not be considered an exclusive feature of patients with osteo-mineral disorders. Vitamin D is capable to reduce free fatty acids (FFA) induced insulin resistance both in peripheral tissues and in hepatocytes. Positive associations between 25(OH)D deficiency and the prevalence of obesity have been proved. Recent studies suggested that adequate serum 25(OH)D 
levels could be associated with increased adipocyte activity and oxidation of fat with the potential of improving of insulin sensitivity which can lead to weight loss $[6,7]$. Obese individuals tend to have lower serum vitamin $\mathrm{D}$ level than those with normal weights $[8,9]$. Several mechanisms have been proposed to explain the low vitamin D levels in obese people and include the sequestration of $25(\mathrm{OH}) \mathrm{D}$ by fat tissues as well as body size [10].

Non-alcoholic fatty liver disease (NAFLD) is defined as the presence of steatosis in more than $5 \%$ of hepatocytes in the absence of significant alcohol consumption, drug use or hereditary diseases $[11,12]$. NAFLD ranges from simple steatosis, which involves benign fatty infiltration of the liver to a more severe form that involves both steatosis and necroinflammation, known as nonalcoholic steatohepatitis (NASH) which carries increased risks of hepatic fibrosis and cirrhosis [13]. The prevalence of NAFLD had increase over the last two decades which run paralleled the dramatic rise in childhood obesity worldwide $[14,15]$.

There were no previous studies about serum vitamin D level in the NAFLD children. The aim of this work was to assess the vitamin D status in a group of Egyptian children with nonalcoholic fatty liver disease.

\section{Methods}

Forty-seven patients were selected randomly from those recruited to the pediatric hepatology outpatient clinics in 3 Egyptian centers between Jan 2014 and May 2015 (El Sahel teaching hospital, Minia University children's hospital and Egyptian national liver institute). Enrolled patients had fulfilled the following criteria: Age (5-15 years) and proved to have NAFLD by ultra-sonographic examination. Candidates were excluded according to the following criteria: Diagnosis of autoimmune liver disease, positive test results for either hepatitis B surface antigen or hepatitis $\mathrm{C}$ antibody, history of cardiovascular disease, renal dysfunction, hypo or hyperthyroidism, current use of drugs known to influence 25(OH)D metabolism including glucocorticoids, non-steroidal anti-inflammatory drugs and calcium/vitamin D supplements, severe disability or bone fracture, current infectious condition, presence of tumor, severe anemia and children with type I or II diabetes.

Another 23 healthy age and sex matched children were included as controls selected from healthy school children after exclusion of NAFLD (by ultra-sonographic examination).

All the participants were subjected to detailed clinical history taking and complete physical examination. Measurements of weight $(\mathrm{kg})$ and height $(\mathrm{cm})$ were used to calculate the body mass index (BMI) $\left[=\left(\mathrm{kg} / \mathrm{m}^{2}\right)\right]$. BMI readings were plotted on the percentile growth charts for BMI between the age of 2 and 20 years. Childhood obesity was defined as BMI $\geq 97$ th percentile while between 3th and 96th centile was considered normal [16].

\section{Sampling}

Five $\mathrm{ml}$ of venous blood were collected after an overnight fasting in vacutainers without additive allowed to clot for $30 \mathrm{~min}$ at room temperature and centrifuged at $5000 \mathrm{rpm}$ for five minutes. Separated serum was stored into aliquots at $20{ }^{\circ} \mathrm{C}$ until biochemical analysis including liver enzymes (ALT \& AST), fasting blood glucose (FBG), total serum cholesterol, triglyceride (TG) and HDL cholesterol (were analyzed enzymatically using kit obtained from Randox Laboratories Limited, Crumlin, UK). Fasting blood glucose and fasting insulin (FINS) was quantified by an electrochemiluminescence immunoassay. Insulin resistance (IR) was assessed by calculating the homeostasis model assessment index for insulin resistance $(\mathrm{HOMA}-\mathrm{IR})$ [FBG $(\mathrm{mmol} / \mathrm{L}) \times$ FINS $(\mathrm{mU} / \mathrm{L}) / 22.5$ ] [17]. C reactive protein (CRP) concentration was measured using a particle-enhanced immunonephelometry. Serum vitamin D was measured by ELISA (Immunodiagnostic Systems, Louvain-la-Neuve, Belgium).

Liver ultrasound was performed using (GE Healthcare, Logiq 5 pro. ultra sonogram. Real time unit with a $5 \mathrm{MHz}$ abdominal transducer).

Because performing liver biopsies for the exclusive purpose of a study is inappropriate (i.e. for assaying $25(\mathrm{OH}) \mathrm{D}$ in NAFLD children), ultra-sonographic diagnosis of NAFLD was made for all study participants according to Saverymuttu et al.,1986 who graded steatosis into four grades: $0=$ absent, $1=$ mild, $2=$ moderate and 3 = severe [18].

The study was carried out according to the principles of the Declaration of Helsinki, and its appendices [19] and was approved by the hospital ethical review board in El Sahel teaching hospital (code 114, August,2015), Minia University hospital (code 75.a, August, 2015) and national liver institute (code 18.c, September, 2015). Written informed consents from the patients' caregivers were obtained for the use of their study-related information and for participation in the ongoing research.

\section{Statistical analysis}

The SPSS (Statistical Package for the Social Sciences) statistical software suite, version 16.0, was used for all statistical analyses (SPSS Inc, Chicago, IL, USA). Data with normal distribution were expressed as the mean values \pm SD and were assessed by unpaired Student's $t$-test to evaluate inter-group (NAFLD $v s$ control) differences. Comparative analyses of categorical variables were carried out by the chi-square test. The relationship between serum 25(OH)D and demographic and 
clinical variables were evaluated by partial correlation testing. In addition, regression analysis was performed to identify independent factors of NAFLD. A two-tailed $p$ value $<0.05$ indicated statistical significance.

\section{Results}

Compared to the control group, the NAFLD patients had lower levels of serum 25(OH)D and higher values of BMI centile, fasting blood glucose, serum triglyceride, fasting insulin level, HOMA-IR, ALT, AST and GGT levels (Table 1).

Significant differences were found between patients and controls regarding many laboratory data. Vitamin D level is decreased in patients compared with healthy controls $(p=0.001)$ (Table 2, Fig. 1).

With stratification of the studied group by grades of steatosis (absent, mild, moderate and severe), five (10.6 \%) patients had no steatosis, 6 (12.8 \%) had mild steatosis, 17 (36.2 \%) had moderate steatosis and 19 (40.4\%) had sever steatosis. Significant differences were found between grades of steatosis regarding serum $25(\mathrm{OH}) \mathrm{D}$ except between the moderate and severe group $(p=1)$ (Table 2, Fig. 2).
While vitamin D level is decreased in NAFLD children, it could not be considered as a Dependant factor in these patients $(p=0.53)$ (Table 3$)$.

Forty-nine percent $(94 \%)$ of involved patients were obese. Despite of this, there was a non-significant positive correlation between BMI centile and grades of steatosis $(p=0.94)$.

No significant correlation between serum 25(OH)D and age $(p=0.11, r=-0.24)$, BMI centile $(p=0.6, r=-0.8)$, AST $(p=0.83, r=0.03)$, ALT $(p=0.45, r=-0.11)$, GGT $(p=0.054, r=-0.28)$, serum albumin $(p=0.31, r=0.15)$, total $(p=0.24, r=-0.17)$ and direct bilirubin $(p=0.6$, $r=-0.77)$, serum creatinine $(p=0.69, r=0.06)$, fasting glucose $(p=0.16, r=-0.21)$ and fasting insulin levels $(p=$ $0.72, r=-0.06)$, serum TG $(p=0.41, r=0.12)$, serum cholesterol $(p=0.28, r=-0.16)$, LDL $(p=0.46, r=0.11)$, HDL $(p=0.57, r=-0.09)$ and CRP $(p=0.66, r=-0.7)$, HOMAIR $(p=0.74, r=-0.07)$. Significant negative correlation was found between serum $25(\mathrm{OH}) \mathrm{D}$ and the grades of steatosis ( $p<0.001, r=-0.84)$ (Fig. 3).

Serum $25(\mathrm{OH}) \mathrm{D}$ deficiency was not a dependent risk factor for development of childhood nonalcoholic hepatic

Table 1 Some clinical and laboratory data of both studied groups

\begin{tabular}{|c|c|c|c|c|}
\hline \multicolumn{2}{|l|}{ Parameter } & \multirow{2}{*}{$\begin{array}{l}\text { NAFLD patients } \\
(\mathrm{No}=47)\end{array}$} & \multirow{2}{*}{$\begin{array}{l}\text { Controls } \\
(\mathrm{No}=23)\end{array}$} & \multirow[t]{2}{*}{$P$-value } \\
\hline & & & & \\
\hline$\overline{\text { Age }}$ & Mean \pm SD & $11.13 \pm 2.7$ & $10.6 \pm 3.1$ & 0.43 \\
\hline \multirow[t]{2}{*}{ Sex } & Male (\%) & 19 (40.4 \%) & $9(39.1 \%)$ & \multirow[t]{2}{*}{0.32} \\
\hline & Female (\%) & 28 (59.6\%) & $14(60.9 \%)$ & \\
\hline BMI centile (th) & Mean \pm SD & $96.8723 \pm 0.5$ & $92.2 \pm 9.3$ & $<0.001^{*}$ \\
\hline ALT $(U / L)$ & Mean \pm SD & $63.8 \pm 31.1$ & $27.6 \pm 5.7$ & $<0.001^{*}$ \\
\hline AST $(U / L)$ & Mean \pm SD & $58.8 \pm 22.9$ & $28.8 \pm 8.7$ & $<0.001^{*}$ \\
\hline GGT (U/L) & Mean \pm SD & $53.8 \pm 21.6$ & $34.5 \pm 9.4$ & $<0.001^{*}$ \\
\hline Serum albumin (mg/dl) & Mean \pm SD & $3.5 \pm 0.52$ & $3.9 \pm 0.2$ & $<0.001^{*}$ \\
\hline Total bilirubin (mg/dl) & Mean \pm SD & $1.4 \pm 0.71$ & $0.71 \pm 0.2$ & $<0.001^{*}$ \\
\hline Direct bilirubin (mg/dl) & Mean \pm SD & $0.32 \pm 0.2$ & $0.14 \pm 0.05$ & $<0.001^{*}$ \\
\hline Alkaline phosphatase (U/L) & Mean \pm SD & $214.4 \pm 56.6$ & $186.2 \pm 46.4$ & $0.01^{*}$ \\
\hline $\mathrm{CRP}(\mathrm{mg} / \mathrm{dl})$ & Mean \pm SD & $56 \pm 18.1$ & $5 \pm 3.1$ & $<0.001^{*}$ \\
\hline Serum creatinine $(\mathrm{mg} / \mathrm{dl})$ & Mean \pm SD & $0.81 \pm 0.35$ & $1 \pm 0.19$ & $<0.001^{*}$ \\
\hline Serum cholesterol (mg/dl) & Mean \pm SD & $198.3 \pm 27.1$ & $163.8 \pm 27.5$ & $<0.001^{*}$ \\
\hline Serum triglyceride $(\mathrm{mg} / \mathrm{dl})$ & Mean \pm SD & $191.3 \pm 37.6$ & $157.7 \pm 32.9$ & $<0.001^{*}$ \\
\hline Serum LDL (mg/dl) & Mean \pm SD & $104.7 \pm 36.2$ & $108.13 \pm 11.1$ & 0.52 \\
\hline Serum HDL (mg/dl) & Mean \pm SD & $37.3 \pm 9.7$ & $43.4 \pm 8.1$ & $0.002^{*}$ \\
\hline Fasting Blood glucose (mg/dl) & Mean \pm SD & $143.3 \pm 33.9$ & $100.17 \pm 14.7$ & $<0.001^{*}$ \\
\hline Fasting insulin (mU/ml) & Mean \pm SD & $11.7 \pm 4.8$ & $4.5 \pm 2.9$ & $<0.001^{*}$ \\
\hline HOMA-IR & Mean \pm SD & $76.6 \pm 41.4$ & $20.7 \pm 16.3$ & $<0.001$ \\
\hline Serum 25(OH) D (nmol/L) & Mean \pm SD & $52.1 \pm 41.3$ & $104.7 \pm 36.2$ & $<0.001^{*}$ \\
\hline
\end{tabular}

*Significant ( $p$ value <0.05), BMI body mass index, ALT alanine aminotransferase, AST aspartate aminotransferase, GGT gamma glutamyl transferase, $C R P C$ reactive protein, $L D L$ Low density lipoprotein, HDL High density lipoprotein, HOMA-IR homeostasis model assessment index for insulin resistance and $25(\mathrm{OH}) \mathrm{D} 25$ hydroxy vitamin D 
Table 2 Comparison between different grades of steatosis regarding serum vitamin $\mathrm{D}$ level

\begin{tabular}{llllllll}
\hline Parameter & Grade & Grade & Grade & Grade & Grade & Grade All \\
& $0 \& 1$ & $0 \& 2$ & $0 \& 3$ & $1 \& 2$ & $1 \& 3$ & $2 \& 3$ & \\
\hline$p$ - value & 0.05 & $<0.001^{*}$ & $<0.001^{*}$ & $<0.001^{*}$ & $<0.001^{*}$ & 1.00 & $<0.001^{*}$
\end{tabular}

${ }^{*}$ Significant $(p$-value $<0.05)$

steatosis as shown by multiple stepwise regression analysis for the grades of steatosis $(p=0.54)$ (Table 3$)$.

\section{Discussion}

To our knowledge, there is no previous study about the level of serum vitamin D in NAFLD in children. In this study, serum $25(\mathrm{OH}) \mathrm{D}$ was decreased compared with controls. This comes in agreement with Targher et al., 2007 who performed a liver biopsy to confirm NAFLD. They found significantly lower levels of serum 25(OH)D in NAFLD patients than in controls [20].

Obesity was found in most NAFLD children but no significant correlation was detected between serum $25(\mathrm{OH}) \mathrm{D}$ and BMI. Excess body fat results in its increased sequestration and low availability and, as a consequence, low serum 25(OH) D levels [10, 21]. Further study suggested the dilution of vitamin $\mathrm{D}$ in body tissue mass (in fat cell mass as well as extracellular fluid) rather than sequestration in the fat tissue [22].

Vitamin D dose response in obese subjects is about $30 \%$ lower than the response in non-obese ones. In addition, the dose-response curves in obese and nonobese subjects are effectively parallel.

Lagunova et al. 2009 found that obese patients have about $20 \%$ lower levels of serum 25(OH)D compared with normal weight or overweight persons [23].

Low serum 25(OH)D level might play a role in NAFLD pathogenesis, possibly via suppression of its antiinflammatory properties. Indeed, chronic inflammation is considered a key factor in NAFLD progression [24, 25].

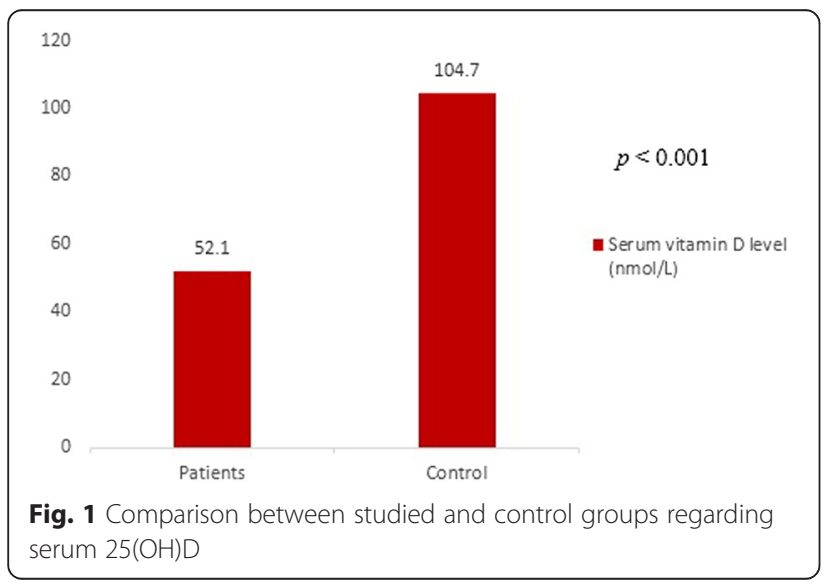

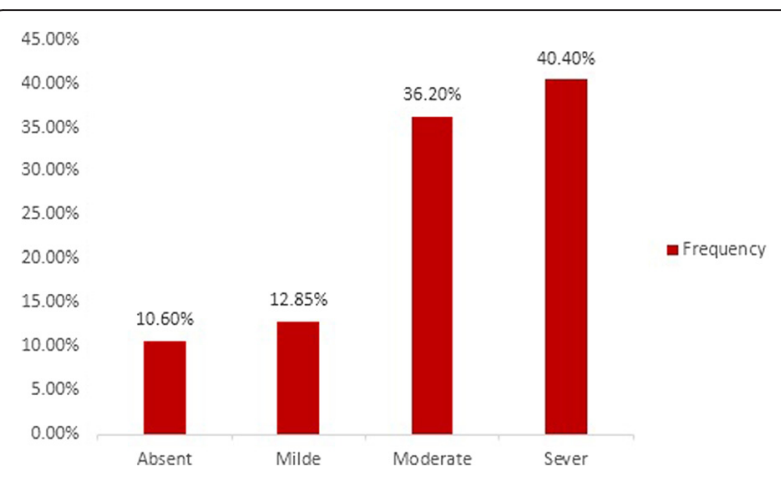

Fig. 2 Frequency of different grades of steatosis in NAFLD patients

Increased visceral adiposity promotes the release of both free fatty acids and pro-inflammatory cytokines [26]. In turn, activation of inflammation within the liver, possibly via increased nuclear factor $\mathrm{k} B(\mathrm{NFkB})$ activity, thus promoting downstream transcription of pro-inflammatory cytokines and ultimately perpetuating a vicious cycle [27]. Increased levels of serum $25(\mathrm{OH}) \mathrm{D}$ might act to reduce the development/progression of NAFLD by countering these inflammatory processes. Lower serum 25(OH)D levels are associated with higher circulating inflammatory markers [28-31].

Inadequate $25(\mathrm{OH}) \mathrm{D}$ status in healthy individuals is associated with increases in both vascular endothelial cell NFkB protein expression and vascular NFkB signaling Hence, low serum $25(\mathrm{OH}) \mathrm{D}$ levels may promote these inflammatory processes that are also involved in the development and progression of NAFLD [32].

A different study opposes our results supporting that CYP27A1 and CYP2R1 enzyme expression, as well as the ability to hydroxylize vitamin $\mathrm{D}_{3}$, are well persevered in NASH and do not contribute to lowered serum 25(OH)D levels [33].

We found no significant correlation between BMI and serum $25(\mathrm{OH}) \mathrm{D}$ despite of obesity in a large number of patient. This is against Saneei et al., 2013 who proved significant inverse weak correlation between serum 25(OH)D levels and BMI in adult populations [34].

In the present study there was inverse negative correlation between vitamin D and the grades of steatosis. Jablonski et al., 2013 proved a strong inverse relationship between NAFLD and 25(OH)D levels [35]. Vitamin D directly regulates the metabolism of FFAs via its action on peroxisome proliferator-activated receptor gamma (PPAR- $\gamma$ ) [36]. Studies were made to prove weather fatty

Table 3 Univariate logistic regression analysis of serum 25(OH)D and hepatic steatosis

\begin{tabular}{lclc}
\hline Variable & Odd Ratio & Confidence interval $(\mathrm{Cl})$ & $p$-value \\
\hline Serum $25(\mathrm{OH}) \mathrm{D}$ & 0.888 & $0.61-1.6$ & 0.53 \\
\hline
\end{tabular}




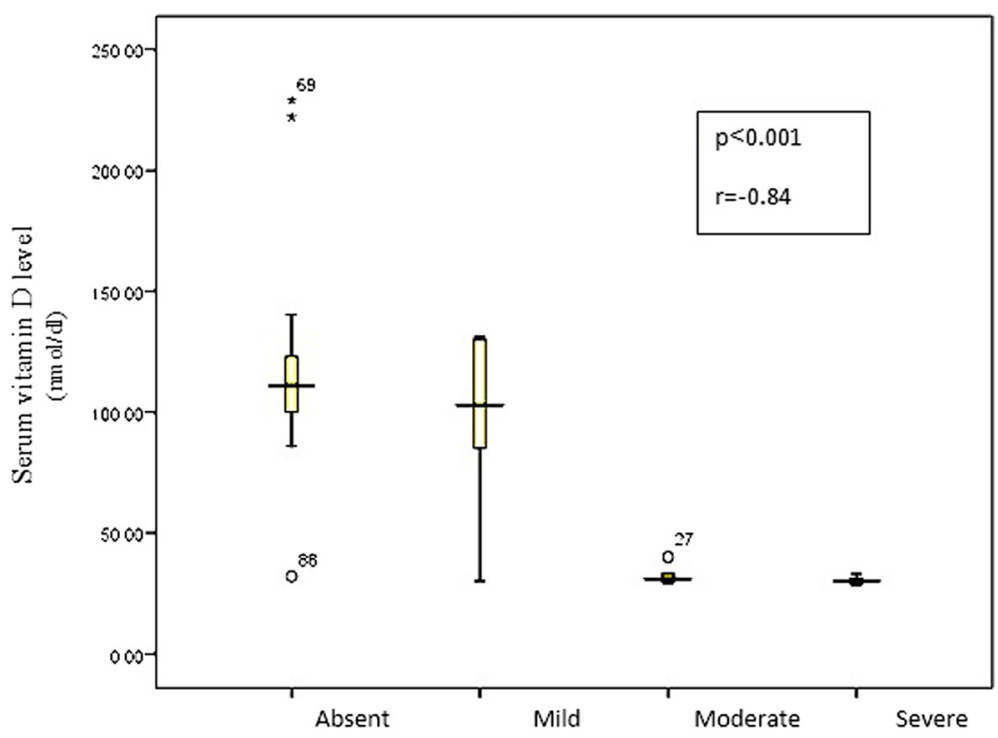

Fig. 3 Comparison between different grades of steatosis regarding the level of serum vitamin D

liver disease could be a consequence of increased inflammation, or does inflammation increase hepatic steatosis. An association between hepatic steatosis and elevation of CRP, a protein produced predominately by the liver under conditions of inflammation found by Ndumele and colleagues [37]. Hepatic steatosis may exaggerate the synthesis of high sensitivity CRP or other mediators by the liver, thereby increasing its systemic levels. Other laboratory studies have shown that inflammation is not a consequence of steatosis, but could be its cause [38, 39]. Thus, in patients with NAFLD, the inflammatory response likely functions as an amplification loop contributing to hepatic steatosis.

Rhee et al., 2013 found a minor but significant difference in $25(\mathrm{OH}) \mathrm{D}$ levels between patients with and without NAFLD [40].

\section{Conclusions}

Serum vitamin D level decreases in children with NAFLD. This low serum vitamin D is associated with higher stages of steatosis but not with BMI.

\section{Limitations of the study}

1. The small number of patients included in the study owing to the rarity of hepatic steatosis in children.

2. Liver biopsy could not be performed to either patients or controls for accurate diagnosis of NAFLD considering the ethics of humanity.

\section{Abbreviations}

$25(\mathrm{OH}) \mathrm{D}$, twenty five hydroxyl vitamin $\mathrm{D} ; 25(\mathrm{OH})_{2}$ D,twenty five di hydroxyl vitamin D; ALP, alkaline phosphatase; ALT, alanine aminotransferase; AST, aspartate aminotransferase; BMI, body mass index; CRP, C reactive protein;
ELISA, enzyme-linked immunosorbent assay; FFAs, free fatty acids; FINS, fasting insulin; FPG, fasting blood glucose; GGT, gamma glutamyl transferase; HDL, High density lipoprotein; HOMA-IR, homeostatic model assessment of insulin resistance; IL-6, interleukin-6; IR, insulin resistance; LDL, low density lipoprotein; NAFLD, nonalcoholic fatty liver disease; NASH, nonalcoholic steatohepatitis; PPAR- $\gamma$, peroxisome proliferator-activated receptor gamma; TG, triglycerides; UVB, ultraviolet ray B; VDR, vitamin D resistance; WHO, World Health Organization

\section{Acknowledgment}

To the radiology departments in El Sahel teaching hospital, Minia university hospital and Egyptian national hepatology institute.

\section{Funding}

No financial support from any institutions.

\section{Authors' contributions}

$A A, G L, A M$ and MA participated in the study design, interpreted the data and wrote the manuscript. LA and AM analyzed the genetic data and RM, MA, AK and AM participated to discuss the results and to write the manuscript. All authors listed in a manuscript have contributed substantially to the work and seen and approved the submitted version. No part of the work has been published before.

\section{Competing interests}

The authors declare that they have no competing interests.

\section{Author details}

1Department of Biochemistry, National Hepatology and Tropical Medicine Institute, Cairo, Egypt. ${ }^{2}$ Pediatric Department, El Sahel teaching hospital, Cairo, Egypt. ${ }^{3}$ Pediatric Department, Minia University, El Minya, Egypt. ${ }^{4}$ Public health Department, Faculty of Medicine, Ain Shams University, Cairo, Egypt. ${ }^{5}$ Microbiology and Immunology Department, Faculty of Pharmacy, Cairo University, Cairo, Egypt. ${ }^{6}$ Department of Clinical Nutrition, Faculty of Applied Medical Science, King Abdul-Aziz University, Jeddah, Kingdom of Saudi Arabia.

Received: 3 June 2016 Accepted: 5 August 2016 Published online: 19 August 2016

\section{References}

1. Holick M. Vitamin D, deficiency. N Engl J Med. 2007;357(3):266-81. 
2. De Luca HF. Overview of general physiologic features and functions of vitamin D. Am J Clin Nutr. 2004;80(6):1689S-96S.

3. Pittas AG, Lau J, Hu FB, Dawson-Hughes B. The role of vitamin D and calcium in type 2 diabetes: a systematic review and meta-analysis. J Clin Endocrinol Metab. 2007;92:2017-29.

4. Forouhi NG, Luan J, Cooper A, Boucher BJ, Wareham NJ. Baseline serum 25-hydroxy vitamin $d$ is predictive of future glycemic status and insulin resistance: The Medical Research Council Ely Prospective Study 1990-2000 Diabetes. 2008;57:2619-25.

5. Hypponen E, Boucher BJ, Berry DJ, Power C. 25-hydroxyvitamin D, insulinlike growth factor 1 and metabolic syndrome at age 45y: a cross-sectional study in the 1958 British birth cohort. Diabetes. 2008;57:298-305.

6. Rosenblum JL, Castro VM, Moore CE, Kaplan LM. Calcium and vitamin D supplementation is associated with decreased abdominal visceral adipose tissue in overweight and obese adults. Am J Clin Nutr. 2012;95(1):101-8.

7. Mai X-M, Chen Y, Camargo Jr CA, Langhammer A. Cross-Sectional and Prospective Cohort Study of Serum 25-Hydroxyvitamin D Level and Obesity in Adults: The HUNT Study. Am J Epidemiol. 2012;175:1029-36.

8. Compston JE, Vedi S, Ledger JE, Webb A, Gazet JC, Pilkington TRE. Vitamin D status and bone histomorphometry in gross obesity. Am J Clin Nutr. 1981;34:2359-63.

9. Hey H, Stockholm KH, Lund BJ, Sorensen OH. Vitamin D deficiency in obese patients and changes in circulating vitamin $D$ metabolites following jejunoileal bypass. Int J Obes. 1982;6:473-9.

10. Wortsman J, Matsuoka LY, Chen TC, Lu Z, Holick MF. Decreased bioavailability of vitamin D in obesity. Am J Clin Nutr. 2000;72:690-3.

11. Tiniakos DG, Vos MB, Brunt EM. Nonalcoholic fatty liver disease: pathology and pathogenesis. Annu Rev Pathol. 2010;5:145-71.

12. Chalasani N, Younossi Z, Lavine JE, Diehl AM, Brunt EM, Cusi K, Charlton M, Sanyal AJ. The diagnosis and management of non-alcoholic fatty liver disease: Practice guideline by the American Association for the Study of Liver Diseases, American College of Gastroenterology, and the American Gastroenterological Association. Hepatology. 2012;55:2005-23.

13. Day CP. Natural history of NAFLD: remarkably benign in the absence of cirrhosis. Gastroenterology. 2005;129:375-8.

14. Janssen I, Katzmarzyk PT, Boyce WF, et al. Comparison of overweight and obesity prevalence in school-aged youth from 34 countries and their relationships with physical activity and dietary patterns. Obes Rev. 2005;6:123-32.

15. Ji CY. Cooperative Study on Childhood Obesity: Working Group on Obesity in China (WGOC). The prevalence of childhood overweight/obesity and the epidemic changes in 1985-2000 for Chinese school-age children and adolescents. Obes Rev. 2008;9(1):78-81.

16. Official 2000 centers for centers for disease control (CDC) growth charts, created by the National Center for Health Statistics (NCHS). www.cdc.gov/nchs

17. Matthews DR, Hosker JP, Rudenski AS, Naylor BA, Treacher DF, Turner RC. Homeostasis model assessment: insulin resistance and beta-cell function from fasting plasma glucose and insulin concentrations in man. Diabetologia. 1985;28:412-9.

18. Saverymuttu SH, Joseph AE, Maxwell JD. Ultrasound scanning in the detection of hepatic fibrosis and steatosis. Br Med J. 1986;292:13-5.

19. World Medical Association Declaration of Helsinki, Ethical Principles for Medical Research involving human subjects. Available from: http://www. wma.net/e/policy/b3.htm.

20. Targher G, Bertolini L, Scala L, Cigolini M, Zenari L, Falezza G, et al. Associations between serum 25-hydroxyvitamin D3 concentrations and liver histology in patients with non-alcoholic fatty liver disease. Nutr Metab Cardiovasc Dis. 2007:17(7):517-24.

21. Rosenstreich SJ, Rich C, Volwiler W. Deposition in and release of vitamin $\mathrm{D}_{3}$ from body fat: evidence for a storage site in the rat. J Clin Invest. 1971;50:679-87.

22. Drincic AT, Armas LA, Van Diest EE, Heaney RP. Volumetric dilution, rather than sequestration best explains the low vitamin $\mathrm{D}$ status of obesity. Obesity (Silver Spring). 2012;20:1444-8.

23. Lagunova Z, Porojnicu AC, Lindberg F, Hexeberg S, Moan J. The dependency of vitamin $D$ status on body mass index, gender, age and season. Anticancer Res. 2009;29(9):3713-20.

24. Targher G, Bertolini L, Poli F, Rodella S, Scala L, Tessari R, et al. Nonalcoholic fatty liver disease and risk of future cardiovascular events among type 2 diabetic patients. Diabetes. 2005;54:3541-6.
25. Targher G, Bertolini L, Padovani R, Zenari L, Zoppini G, Falezza G. Relation of nonalcoholic hepatic steatosis to early carotid atherosclerosis in healthy men: role of visceral fat accumulation. Diabetes Care. 2004;27:2498-500.

26. Targher G, Chonchol M, Miele L, Zoppini G, Pichiri I, Muggeo M. Nonalcoholic fatty liver disease as a contributor to hypercoagulation and thrombophilia in the metabolic syndrome. Semin Thromb Hemost. 2009;35:277-87.

27. Targher G, Chonchol M, Zoppini G, Abaterusso C, Bonora E. Risk of chronic kidney disease in patients with non-alcoholic fatty liver disease: Is there a link? J Hepatol. 2011;54:1020-9.

28. Ngo DT, Sverdlov AL, McNeil JJ, Horowitz JD. Does vitamin D modulate asymmetric dimethylarginine and C-reactive protein concentrations? Am J Med. 2010;123:335-41.

29. Timms PM, Mannan N, Hitman GA, Noonan K, Mills PG, Syndercombe-Court $D$, et al. Circulating MMP9, vitamin D and variation in the TIMP-1 response with VDR genotype: Mechanisms for inflammatory damage in chronic disorders? QJM. 2002;95:787-96.

30. Richards JB, Valdes AM, Gardner JP, Paximadas D, Kimura M, Nessa A, et al. Higher serum vitamin $D$ concentrations are associated with longer leukocyte telomere length in women. Am J Clin Nutr. 2007;86:1420-5.

31. Bellia A, Garcovich C, D'Adamo M, Lombardo M, Tesauro M, Donadel G, et al. Serum 25 -hydroxyvitamin $D$ levels are inversely associated with systemic inflammation in severe obese subjects. Intern Emerg Med. 2011;8(1):33-40

32. Jablonski KL, Chonchol M, Pierce GL, Walker AE, Seals DR. 25-Hydroxyvitamin D deficiency is associated with inflammation-linked vascular endothelial dysfunction in middle-aged and older adults. Hypertension. 2011:57:63-9.

33. Barchetta I, Carotti S, Labbadia G, Vespasiani G, Onetti Muda A, Angelico F, et al. Liver VDR, CYP2R1 and CYP27A1 expression: relationship with liver histology and vitamin D3 levels in patients with NASH or HCV hepatitis. Hepatology. 2012;56(6):2180-7.

34. Saneei P, Salehi-Abargouei A, Esmaillzadeh A. Serum 25-hydroxy vitamin D levels in relation to body mass index: a systematic review and meta-analysis. Obes Rev. 2013;14(5):393-404.

35. Jablonski KL, Jovanovich A, Holmen J, Targher G, McFann K, Kendrick J, et al. Low 25-hydroxyvitamin $D$ level is independently associated with nonalcoholic fatty liver disease. Nutr Metab Cardiovasc Dis. 2013;23(8):792-8.

36. Barchetta I, Angelico F, Del Ben M, Baroni MG, Pozzilli P, Morini S, et al. Strong association between nonalcoholic fatty liver disease (NAFLD) and low $25(\mathrm{OH})$ vitamin $\mathrm{D}$ levels in an adult population with normal serum liver enzymes. BMC Med. 2011;9:85.

37. Ndumele CE, Nasir K, Conceicao RD, Carvalho JA, Blumenthal RS, Santos RD. Hepatic steatosis, obesity, and the metabolic syndrome are independently and additively associated with increased systemic inflammation. Arteriosclerosis, thrombosis, and vascular biology. 2011:31:1927-32.

38. Huang W, Metlakunta A, Dedousis N, Zhang P, Sipula I, Dube JJ, Scott DK, O'Doherty RM. Depletion of liver Kupffer cells prevents the development of diet-induced hepatic steatosis and insulin resistance. Diabetes. 2010;59:347-57.

39. Lanthier N, Molendi-Coste O, Horsmans Y, Van RN, Cani PD, Leclercq IA. Kupffer cell activation is a causal factor for hepatic insulin resistance. Am J Physiol Gastrointest Liver Physiol. 2010;298:107-16.

40. Rhee EJ, Kim MK, Park SE, Park CY, Baek KH, Lee WY, et al. High serum vitamin $D$ levels reduce the risk for nonalcoholic fatty liver disease in healthy men independent of metabolic syndrome. Endocr J. 2013;60(6):743-52.

\section{Submit your next manuscript to BioMed Central and we will help you at every step:}

- We accept pre-submission inquiries

- Our selector tool helps you to find the most relevant journal

- We provide round the clock customer support

- Convenient online submission

- Thorough peer review

- Inclusion in PubMed and all major indexing services

- Maximum visibility for your research

Submit your manuscript at www.biomedcentral.com/submit
Biomed Central 